\title{
Testing the Effects of Seacoast Atmosphere on Tantalum Capacitors
}

\author{
Johanna Virkki ${ }^{1}$ and Pasi Raumonen ${ }^{2}$ \\ ${ }^{1}$ Department of Electronics, Tampere University of Technology, P.O. Box 692, 33101 Tampere, Finland \\ ${ }^{2}$ Department of Mathematics, Tampere University of Technology, P.O. Box 553, 33101 Tampere, Finland
}

Correspondence should be addressed to Johanna Virkki, johanna.virkki@tut.fi

Received 14 January 2011; Accepted 23 March 2011

Academic Editor: Jiun Wei Horng

Copyright ( 2011 J. Virkki and P. Raumonen. This is an open access article distributed under the Creative Commons Attribution License, which permits unrestricted use, distribution, and reproduction in any medium, provided the original work is properly cited.

\begin{abstract}
The goal of this research was to test the effects of seacoast atmosphere on tantalum capacitors. Four tests were chosen for this purpose: the $85 / 85$ test was chosen for testing the effects of the combination of high humidity and high temperature, salt spray testing was done for examining the effects of high humidity and salt, temperature cycling test was applied for testing the effects of temperature changes, and a 100\% RH humidity test was developed for examining the effects of very high humidity. The results show that combination of high humidity and high temperature did not possess a significant risk for these capacitors during their normal use. Very high humidity and radical temperature changes both affected the breakdown voltages of tantalum capacitors. Salt fog caused corrosion of these components and had a small effect on breakdown voltage but did not have an effect on capacitance or ESR.
\end{abstract}

\section{Introduction}

Electronic devices are exposed to varying and harsh environments, and thus common reasons for failures in electronics are environmental contaminants and conditions such as temperature and humidity with other failures deriving, for example, from vibration, ripple voltage, overvoltage, and corrosion. These all affect the reliability of electronic components [1].

Seacoast atmosphere is very stressing environment for electronics. Humidity is very high, temperature can change between extremes, and salt is one of the most corrosive constituents in the atmosphere. Exposure to humidity and salt poses a common risk of corrosion for electronic devices [2-4]. A definition of corrosion is given as the chemical or electrochemical reaction between a material (usually metallic material) and its environment $[5,6]$.

Reliability tests seek to simulate the component's use environment in order to find the effects of environmental stresses. Because such testing is very time consuming, accelerated testing becomes necessary. Accelerated testing means acceleration of failures with the single purpose of quantification of the characteristics of the product at normal use conditions [7]. Thus, in accelerated testing, test conditions are intensified to cut down the time required to obtain a weakening effect similar to one resulting from normal service conditions.

Tantalum capacitors are used in various applications because of their size and achievable levels of capacitance. However, a lot of electronic component failures are found in seacoast-like conditions [8-10]. The starting point for this research was as the following: tantalum capacitors were used in LED matrix display units in seacoast conditions, and breakdown voltages were found to be very low compared to normal use conditions.

Two kinds of tantalum capacitors were used in this paper. Both capacitors were surface mount capacitors that differ only in capacitance and maximum voltage. Tantalum capacitors of a maximum voltage of $50 \mathrm{~V}$, a capacitance of $10 \mu \mathrm{F}$ (referred to as "50/10-capacitor"), and tantalum capacitors of a maximum voltage of $10 \mathrm{~V}$ and a capacitance of $33 \mu \mathrm{F}$ ("10/33-capacitor") were used. Both capacitors have operating temperature from $-55^{\circ} \mathrm{C}$ to $+125^{\circ} \mathrm{C}$. 


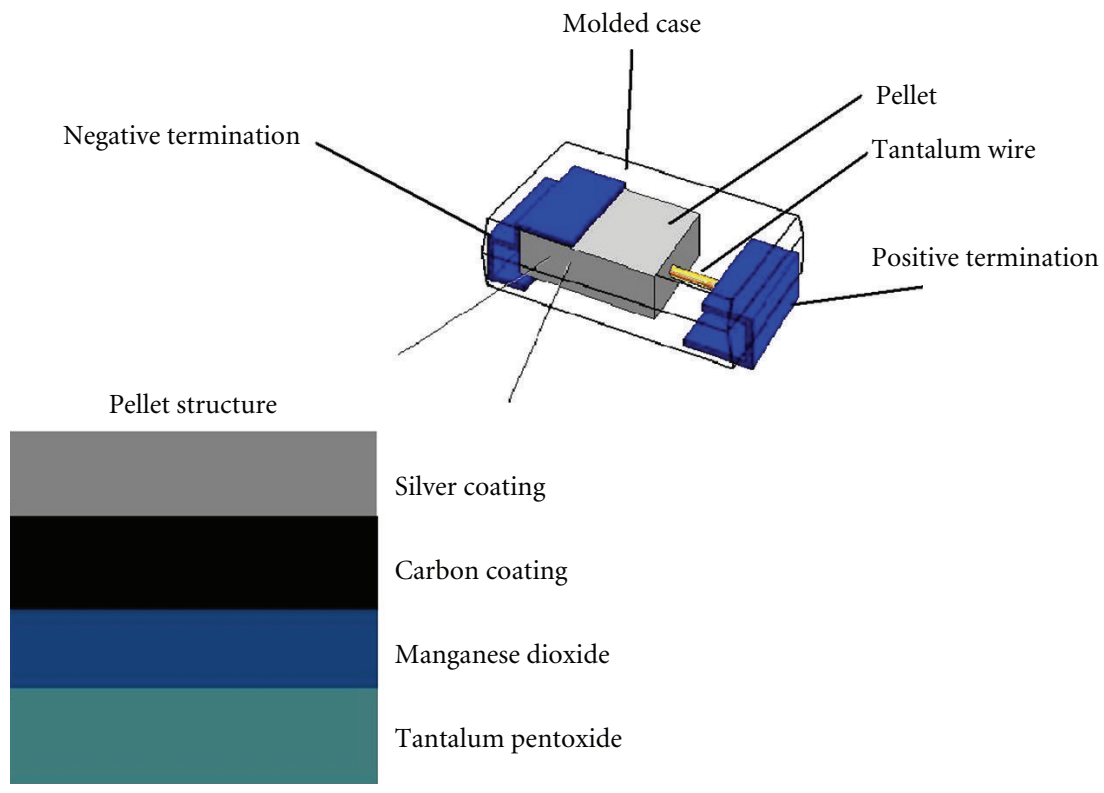

FIgURE 1: Structure of a tantalum capacitor.

The goal of this research was to test the effects of seacoast atmosphere on tantalum capacitors. Four tests (three standard tests and one new test) were chosen for this purpose.

(1) The steady-state temperature humidity bias life test according to standard JESD22-A101C [11] was chosen for testing the effects of combination of high humidity and high temperature during normal use. We tested 36 50/10-capacitors in test conditions and 36 50/10-capacitors in room conditions.

(2) The salt spray test according to standard SFS-ISO 9227 [12] was chosen for testing the effects of combination of high humidity and salt. We tested 10 10/33-capacitors for each chosen testing time.

(3) The temperature cycling test, according to the standard JESD22-A104D [13] was chosen for testing the effects of temperature changes. We tested 18 50/10capacitors.

(4) A $100 \%$ relative humidity $(\mathrm{RH})$ test was developed for examining the effects of very high humidity. We tested 18 50/10-capacitors for each chosen testing time.

\section{Tantalum Capacitors}

In this section, the structure and substantial failures of these capacitors are reviewed.

2.1. Structure of Tantalum Capacitors. A tantalum capacitor consists of three main elements: an anode, a cathode, and a dielectric layer of tantalum pentoxide that separates them. The capacitor contains an embedded tantalum pellet (anode), surrounded by a tantalum pentoxide, amorphous dielectric layer. The cathode is a semiconductor, manganese dioxide. This pellet is coated with carbon and then with silver to provide the final connecting layer to the cathode terminal. The tantalum wire passes through these layers and connects the positive termination to the tantalum. The negative termination of the capacitor is attached with a silver adhesive to the silver paint layer. Tantalum capacitor structure is shown in Figure $1[14,15]$.

2.2. Failures of Tantalum Capacitors. The reliability of tantalum capacitors is greatly affected by environmental conditions. In addition, strong ripple currents and mechanical stresses can cause failures $[16,17]$. This section is a review of conditions that usually have the biggest effect on tantalum capacitor reliability and the failure mechanisms they may cause.

2.2.1. Effects of Humidity. The reliability of a tantalum capacitor is heavily influenced by humidity with various effects inside the capacitor. Moisture can penetrate the polymer encapsulating material and degrade the characteristics of the capacitor. These effects can later cause the capacitor to fail [18].

Numerous humidity-related failure mechanisms have been reported [18-20], but the reason behind the failure mechanisms of tantalum capacitors in humid environments has not been clearly explained.

Tantalum capacitors are manufactured by sintering highly dispersed micrometer-size tantalum powder to form sponge-like porous pellets. After a tantalum pellet is anodized and a tantalum pentoxide dielectric is formed, a cathode electrode is applied. The following pyrolysis transforms manganese nitrate into a conductive manganese dioxide cathode layer. The high porosity of the pellet makes it difficult for the whole area of the dielectric to be covered with manganese oxide, and some areas may remain uncovered. 
Besides, during the pyrolyses, the substance shrinks, creating microscopic voids and gaps between the manganese dioxide and the nearby surface of tantalum pentoxide $[18,21]$. Due to the high dielectric permittivity of tantalum pentoxide, few nanometer gaps can already significantly reduce the capacitance of a surface element compared to a situation without gaps. This indicates the presence of capillary-like passive cells without a cathode contact. The size of the passive cells is most likely in the range from tens of nanometers to micrometers [18].

Variations in capacitance in dry and humid environments have been explained by the passive cells remaining inactive until activated by absorbed moisture. In humid environments, moisture diffuses into the passive cells and creates an extremely thin conductive layer on the surface of the dielectric material. This water layer then works as a cathode electrode, connecting the passive area with the surrounding manganese dioxide and increasing the capacitance of the part $[18,22]$. To activate a sleeping cell, the resistance of the moisture layer should be low enough to provide necessary electrical conductivity over the passive area. The sleeping cells are most likely not empty, clean tantalum pentoxide cylinders, as assumed above, but have some contamination remaining after the manufacturing processes. In humid environments, sleeping cells may become active in various ways. These processes include formation of a moistureadsorbed layer, capillary condensation, and moisturizing of the hygroscopic remnants in the cell $[18,19]$.

Self-healing has also been investigated to explain the humidity-generated failures. The current in a small defect within the dielectric is concentrated into a small, finite volume of the cathode plate in contact with the fault site. This concentrated current causes the temperature within this very small region to rise significantly. As the manganese dioxide heats up past $380^{\circ} \mathrm{C}$, it begins to release oxygen, changing the material structure from manganese dioxide to a reduced state. Because this reduced material has much higher resistivity than the original, the current going through this fault is pinched off. This effect is called self-healing, because it eliminates the fault site from the active electrification of the capacitor, though it has not healed the fault site [23]. Storing of the capacitors in humid environments may result in oxidation of the low oxide forms of the manganese oxide layer, thus increasing its conductivity. Oxidation of the reduced manganese oxide at the self-healed defects would reactivate these defects, causing breakdown in the part [21].

Moisture-induced failures may also be related to a moisture-generated silver dendrite growing on cathode contacts. After shorting, these dendrites are "arcing," igniting the manganese oxide and creating a powerful chemical reaction, thus causing catastrophic failure of the part [20]. Moisture intrusion in tantalum capacitors is mostly limited by the molding compound. However, absorbed humidity obviously has harmful effects inside the capacitor.

2.2.2. Effects of Temperature. Temperature varies the rates of physical and chemical reactions that cause failure mechanisms. Thus, temperature is often used in reliability testing as an accelerating parameter. However, at high temperatures, new failure mechanisms previously dormant because of their high activation energy may become activated. Thus, if a test is run at too high temperatures, failure may occur because of a mechanism unlikely during normal operating conditions [24]. Heat, whether generated externally or internally, degrades the performance and reliability of tantalum capacitors [25]. The use of tantalum capacitors at high temperatures has been studied, and such use is found to be challenging [26].

Temperature has also a specific effect inside a tantalum capacitor, known as crystal growth $[27,28]$. The tantalum pentoxide dielectric is considered an amorphous material and inherently thermodynamically sensitive. An amorphous state tends to order and crystallize to reduce its internal energy. Once the dielectric crystallizes, conductivity and leakage current increase. The conductivity of the crystallized structure has been reported to be higher than that of a dielectric in an amorphous state [28]. However, the latest findings suggest that the crystals themselves are good insulators with very limited conductivity [27]. The exact conductivity mechanism related to the crystal phase is not yet fully understood. The increase in leakage current may still be caused by other mechanisms accelerated by the crystal growth. However, studies show that field crystallization may have only a limited impact on the end use of tantalum capacitors [27].

2.2.3. Effects of Temperature Changes. Mechanical stresses related to the soldering of surface mount tantalum capacitors affect their performance and reliability and account for their turn-on breakdowns. In addition, thermomechanical stresses can generate new fault sites in the components. A tantalum capacitor package passing through radical temperature changes may undergo material expansions at different rates depending on each material's thermal expansion and suffer from tensile forces on the pellet structure. During heating, shear forces are exerted on the anode wire. The molded case pushes on the lead frame in one direction and the pellet in another, generating forces that pull the wire away from the anode structure. Once the device has passed though high temperatures and its elements are shrinking while cooling, they may not fit together as they did before the expansion. Compressive forces may appear on the pellet structure and produce fractures. A crack in the dielectric at a corner or edge, when exposed to high stress, may lead to catastrophic failure [29-31]. Besides, during soldering, such a phenomenon may also occur during radical temperature cycling in the field.

\section{Tests for Seacoast Atmosphere}

3.1. High Humidity/High Temperature Test. The steady-state temperature humidity bias life test (known as the $85 / 85$ test, in which temperature is held at a constant $85^{\circ} \mathrm{C}$ and at a $\mathrm{RH}$ of $85 \%$ ) "is performed for the purpose of evaluating the reliability of non-hermetic packaged solid-state devices in humid environments. It employs conditions of temperature, humidity, and bias which accelerate the penetration of 
moisture through the external protective material or along the interface between the external protective material and the metallic conductors which pass through it" [11]. During continued bias testing, heat from power dissipation tends to prevent moisture-related failure mechanisms. In contrast, cycled bias allows moisture to collect during off periods when the device produces no heat. According to the standard, "the die temperature should be quoted with the results whenever it exceeds the chamber ambient by $5^{\circ} \mathrm{C}$ or more, and cycled bias should be chosen if the temperature exceeds the chamber ambient by $10^{\circ} \mathrm{C}$ or more." In this test, the temperature of these passive components did not significantly rise when the voltage was on, so continued bias was chosen.

Such a standard test is often used to identify possible failure types caused by high moisture and high temperature and was used in this research for 36 50/10-capacitors. There were also 36 50/10-capacitors in room conditions. To test the capacitors, we monitored them in real time with continuing DC voltage of $15 \mathrm{~V}$. Capacitor failures were registered as a rise in the leakage current. The current circuit of the measuring instrument measured the leakage current, and the series resistor changed the passing current into a comparable voltage, which was measured in real time. The failure limit was set to measured voltage of $3 \mathrm{~V}$.

3.2. Accelerated Corrosion Test. Accelerated corrosion tests simulate the effects of severe seacoast atmosphere on all exposed surfaces. Basically, the salt spray test procedure involves the spraying of a salt solution onto the samples being tested. This is done inside a temperature-controlled chamber. These are severe conditions. We wanted to find a standard test for testing the effects of salt fog.

Salt atmosphere test according to standard JESD22A107B [32] was the first alternative. "This salt atmosphere test is conducted to determine the resistance of solid state devices to corrosion. During the test, the chamber shall be held at a temperature of $35^{\circ} \mathrm{C}$. The deposit in the test area shall be $30 \pm 10 \mathrm{~g}$ per square meter per $24 \mathrm{~h}$. The $\mathrm{pH}$ of the salt solution shall be maintained between 6.0 and 7.5 when measured at $35^{\circ} \mathrm{C}$ minimum. The minimum duration of exposure of the salt atmosphere test is $24 \mathrm{~h}, 48 \mathrm{~h}, 96 \mathrm{~h}$, or 240 h."

Another suitable standard for salt spray testing is SFSISO 9227 standard [9]. According to the standard, the temperature in the test chamber must be kept in $35^{\circ} \mathrm{C}$ during the test. Recommended testing periods are $2 \mathrm{~h}, 6 \mathrm{~h}$, $24 \mathrm{~h}, 48 \mathrm{~h}, 96 \mathrm{~h}, 168 \mathrm{~h}, 240 \mathrm{~h}, 480 \mathrm{~h}, 720 \mathrm{~h}$, or $1000 \mathrm{~h}$. The standard also states that the duration must be suitable for the tested component. Concentration of sodium chloride $(\mathrm{NaCl})$ in solution must be $50 \mathrm{~g} / \mathrm{L} \pm 5 \mathrm{~g} / \mathrm{L}$, equivalent to $5 \%$ concentration of $\mathrm{NaCl}$ in deionized water. The value of $\mathrm{pH}$ of the solution must be between 6.5 and 7.2 [12].

These two standard tests are very similar, and we designed the test based on SFS-ISO 9227 standard and chose the testing times to be $24 \mathrm{~h}, 96 \mathrm{~h}$, and $240 \mathrm{~h}$, since they are common to both tests. We tested 10 10/33-capacitors for each chosen testing time: we measured capacitance, equivalent series resistance (ESR), and breakdown voltage before testing and after each testing time. For breakdown voltage, the capacitors were tested after each testing time for voltage that was slowly increased (rate of voltage increase: 1 volt per second) from $0 \mathrm{~V}$ to $93 \mathrm{~V}$ provided no failure occurred. The voltage range was chosen because of equipment limitations. The accuracy of measurement was $1 \mathrm{~V}$.

3.3. Temperature Cycling Test. We wanted to find a standard test for testing the effects of temperature changes. The temperature cycling test, according to the standard JESD22A104D [13] "is conducted to determine the ability of components and solder interconnects to withstand mechanical stresses induced by alternating high- and low-temperature extremes. Permanent changes in electrical and/or physical characteristics can result from these mechanical stresses." This standard includes numerous temperature cycling conditions and cycle times. The test usually lasts 500 or 1000 cycles.

We chose nonradical temperature extremes because we wanted to simulate the actual environment and accelerate the effects just a little. In our test, the temperature changed between $-40^{\circ} \mathrm{C}$ and $85^{\circ} \mathrm{C}$, and one cycle lasted for $0.5 \mathrm{~h}$. The test lasted for 500 cycles and had 18 50/10-capacitors tested. We measured breakdown voltages (again between 0 and $93 \mathrm{~V}$ ) before and after temperature cycling.

3.4. 100\% Humidity Test. Our last test is not a standard test. It was developed for measuring the moisture absorption and to study the effects of absorbed moisture. The $100 \%$ $\mathrm{RH}$ test will examine the effects of moisture absorption in a very high humidity conditions on 50/10-capacitors. Before moisture absorption was measured, capacitors were baked for dry out for $24 \mathrm{~h}$ at $125^{\circ} \mathrm{C}$ to remove all moisture from the components, a procedure required by the standard JESD22A113F [33]. 18 50/10-capacitors were first tested for their breakdown voltage, without humidity, to find out if they failed with voltage as the only stress factor. Other capacitors were weighed after each submission- $1 \mathrm{~h}, 21 \mathrm{~h}, 144 \mathrm{~h}$, and 336 h-to $100 \%$ RH. 18 capacitors were weighed after each submission, and their average weights were calculated. After weighting, we measured their breakdown voltages (again between 0 and $93 \mathrm{~V}$ ).

\section{Results and Discussion}

4.1. Effects of the High Humidity/High Temperature Test. The capacitors were tested for $2500 \mathrm{~h}$. None of the tested $36+36$ tantalum capacitors failed during $2500 \mathrm{~h}$. Obviously, $85^{\circ} \mathrm{C}$, $85 \% \mathrm{RH}$, and $15 \mathrm{VDC}$ combined did not represent a stress high enough for the tantalum capacitors to fail.

4.2. Effects of the Accelerated Corrosion Test. Capacitors after $24 \mathrm{~h}, 96 \mathrm{~h}$, and $240 \mathrm{~h}$ in salt spray are seen in Figures 2, 3, and 4 , respectively. The material of capacitor terminations is copper that is plated with $100 \%$ matte tin $(S n)$, which provides sacrificial protection for copper. Lead frames comprising copper with high electrical conductivity are typically utilized as a main lead frame material in electronic products using surface mount technology for assembly. Matte tin 


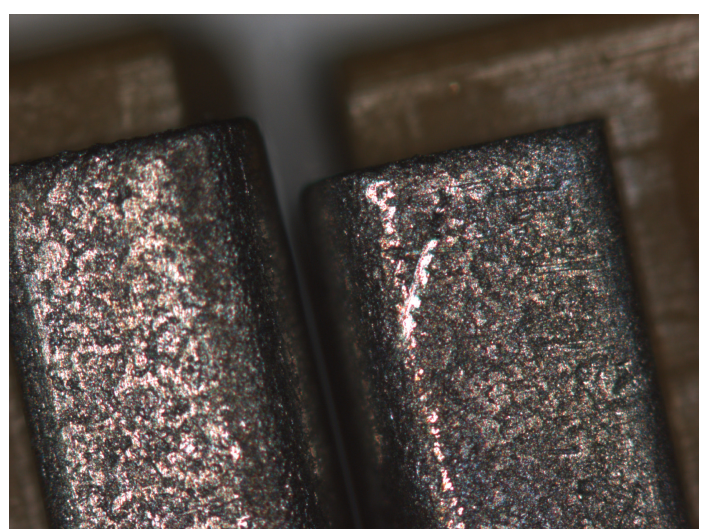

Figure 2: Capacitor after $24 \mathrm{~h}$ in salt spray (left) and a nontested capacitor (right).

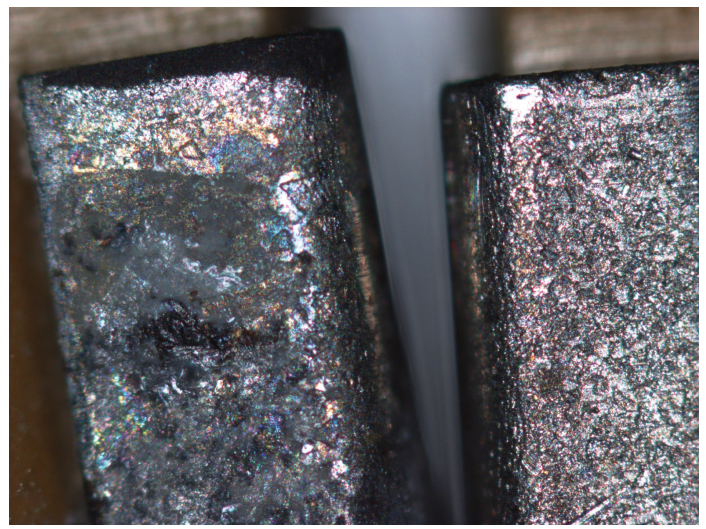

Figure 3: Capacitor after $96 \mathrm{~h}$ in salt spray (left) and a nontested capacitor (right).

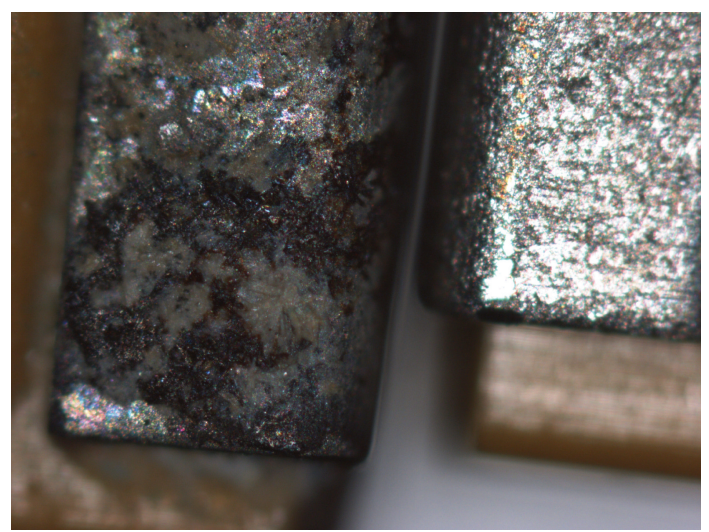

FIGURE 4: Capacitor after $240 \mathrm{~h}$ in salt spray (left) and a nontested capacitor (right).

(in contrast to bright tin) is characterized by low whiskers growing, and therefore it is used in electronics.

In pure water, tin has an excellent corrosion resistance. Except for chlorine, the usual atmospheric pollutants have no significant effects on tin. Tin can resist corrosion by forming a passive film on its surface. A thin protective film rapidly

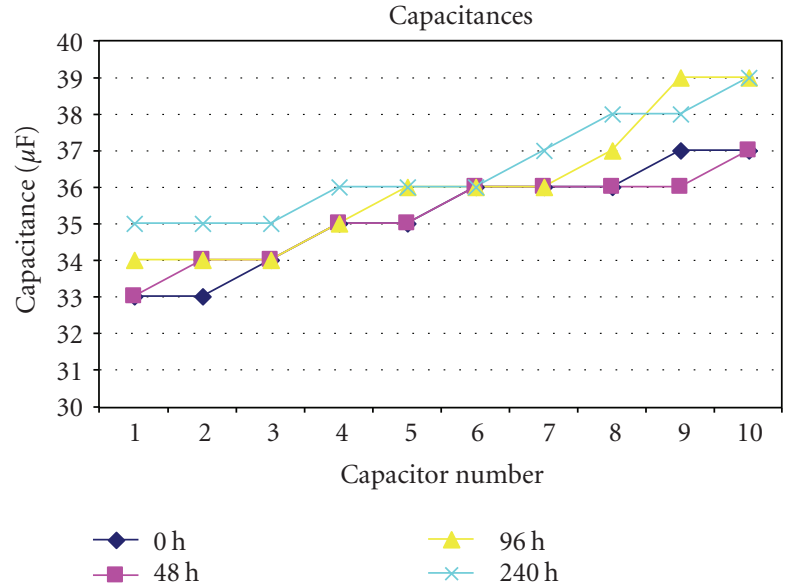

Figure 5: Capacitance measurements for 10/33-capacitors in salt spray (accuracy $\pm 1 \mu \mathrm{F}$ ).

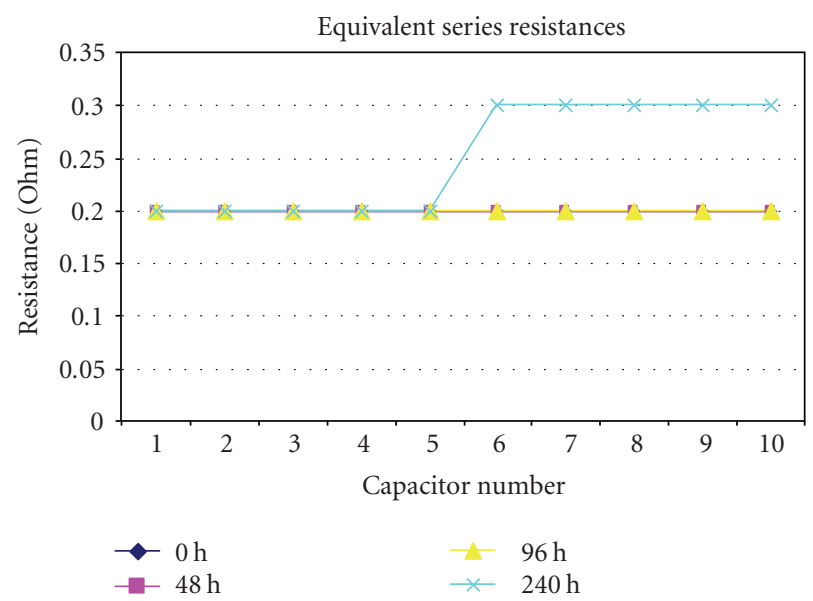

FIGURE 6: ESR measurements for 10/33-capacitors in salt spray (accuracy $\pm 0.1 \Omega$ ).

covers the surface and increases with moisture [34]. Under most atmospheric exposure conditions, the corrosion of tin depends on the formation and stability of the oxide film [35]. Corrosion can be expected at discontinuities in the tin coating, due to galvanic couples formed between the tin and the underlying copper through these discontinuities. In this case, corrosion caused by salt spray decreases the tin plating. Porosity increases as the coating thickness decreases in salt spray.

After $24 \mathrm{~h}$, there is no observable difference between a tested capacitor and a new capacitor. The corroded area is easily observed in the optical micrograph after $96 \mathrm{~h}$, and it grows with time to $240 \mathrm{~h}$.

Capacitances and ESRs of these 10/33-capacitors after $0 \mathrm{~h}, 24 \mathrm{~h}, 96 \mathrm{~h}$, and $240 \mathrm{~h}$ in salt spray can be seen in Figures 5 and 6, respectively. Salt spray testing has no significant effect on ESRs or capacitances of these capacitors. Capacitances increased very slightly, which is probably because of moisture that diffused into the passive cells. 


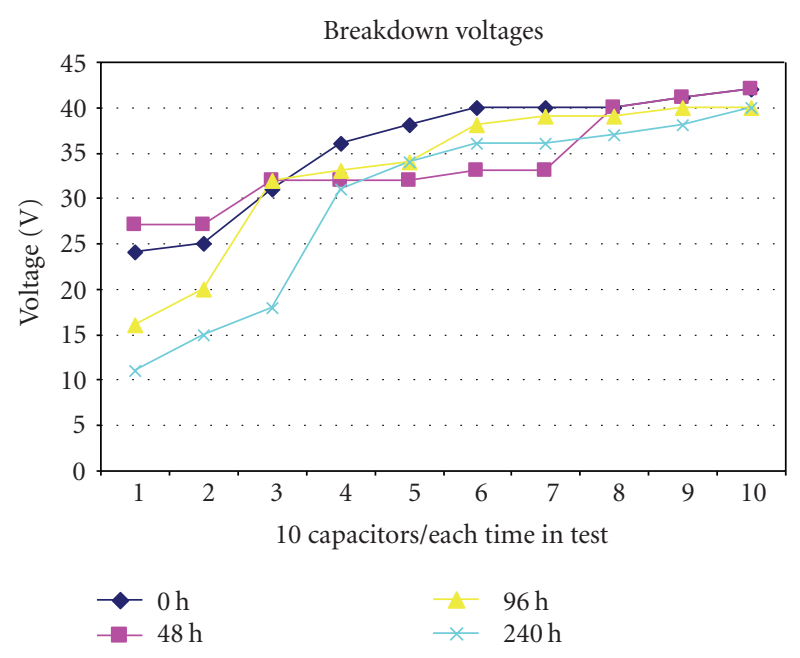

FIGURE 7: Breakdown voltages for 10/33-capacitors in salt spray test (accuracy $\pm 1 \mathrm{~V})$.

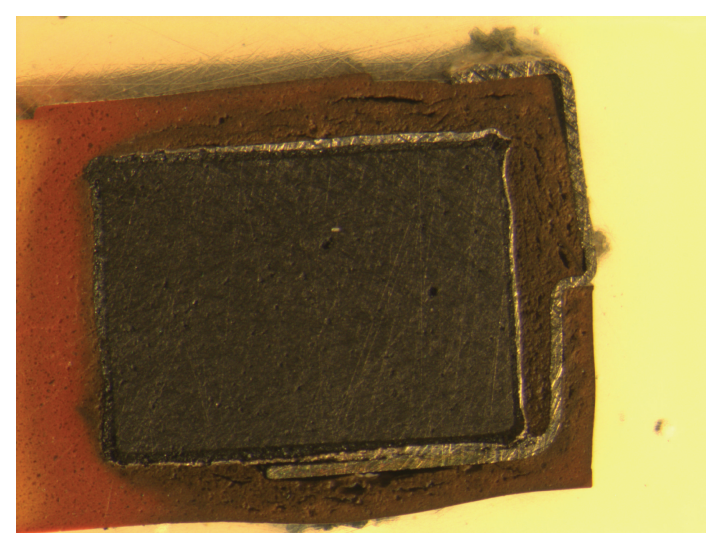

FIgURE 8: An example of a failed capacitor.

Breakdown voltages after salt spray testing can be seen in Figure 7. Maximum voltage given for these capacitors was $10 \mathrm{~V}$. All capacitors failed because of too high voltage, but none of them failed at voltages under $10 \mathrm{~V}$. An example of a failed capacitor can be seen in Figure 8.

To estimate the mean breakdown voltage of these capacitors, from this sample of ten capacitors, a distribution was fitted to the data. The Weibull distribution [36, 37] was used for data analysis, because of its good fit. The Weibull distribution can be fitted to many kinds of data $[7,38]$.

Once a distribution is specified with its parameters, one needs to fit the model (Weibull distribution) to data (breakdown voltages). Parameter estimation was done with Reliasoft's Weibull++ [39], and the least squares method [40] was used. This method is a good choice when the data sets contain only complete data, with no suspensions, such as this data.

Mean voltages to failure with $90 \%$ confidence were calculated for capacitors. The results, including the shape parameters $(\beta)$ and the scale parameters $(\eta)$, are shown in Table 1. Weibull distributions with $\beta>1$ have a failure
TABle 1: Calculated mean voltages to failure (90\% Confidence), shape parameters, and scale parameters for 10/33-capacitors in salt spray test.

\begin{tabular}{lcccc}
\hline & $0 \mathrm{~h}$ & $48 \mathrm{~h}$ & $96 \mathrm{~h}$ & $240 \mathrm{~h}$ \\
\hline Upper $(90 \%)$ & $39 \mathrm{~V}$ & $37 \mathrm{~V}$ & $38 \mathrm{~V}$ & $37 \mathrm{~V}$ \\
Mean & $36 \mathrm{~V}$ & $34 \mathrm{~V}$ & $33 \mathrm{~V}$ & $30 \mathrm{~V}$ \\
Lower $(90 \%)$ & $32 \mathrm{~V}$ & $31 \mathrm{~V}$ & $28 \mathrm{~V}$ & $24 \mathrm{~V}$ \\
$\beta$ & 5.7 & 7.7 & 3.8 & 2.6 \\
$\eta$ & 38 & 36 & 36 & 33 \\
\hline
\end{tabular}

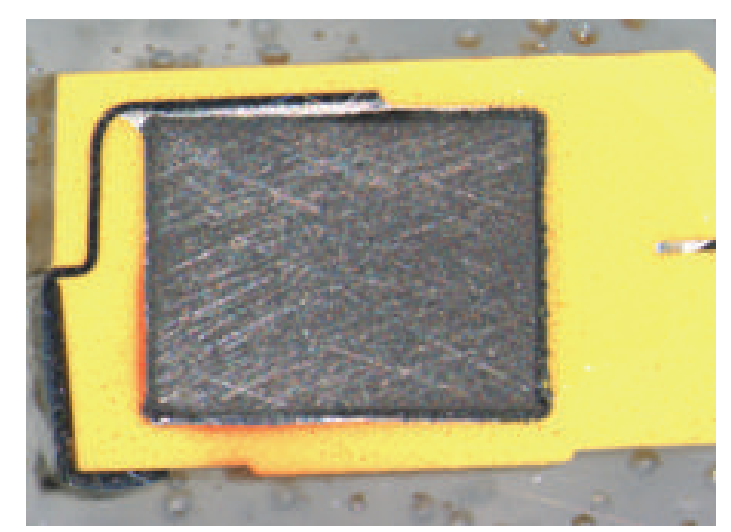

Figure 9: A cross-section of a failed capacitor.

rate that increases with time, which was the case in all tests. Mean breakdown voltages for capacitors after $0 \mathrm{~h}, 48 \mathrm{~h}$, $96 \mathrm{~h}$, and $240 \mathrm{~h}$ were $36 \mathrm{~V}, 34 \mathrm{~V}, 33 \mathrm{~V}$, and $30 \mathrm{~V}$, respectively. This means that salt spray testing decreases breakdown voltage. The scale parameter is equal to the characteristic life; $63.2 \%$ of all values fell below it. The characteristic life for capacitors after $0 \mathrm{~h}, 48 \mathrm{~h}, 96 \mathrm{~h}$, and $240 \mathrm{~h}$ were $38 \mathrm{~V}, 36 \mathrm{~V}, 36 \mathrm{~V}$, and $33 \mathrm{~V}$, respectively, which also shows that lifetime (breakdown voltage) decreased in salt spray. However, changes in breakdown voltage were not radical and thus may not possess a high risk during field use. Tests with a larger amount of components should be done for statistical reliability.

4.3. Results of the Temperature Cycling Test. There were no failures in a group of nontemperature-cycled capacitors between 0 and $93 \mathrm{~V}$. Temperature cycling test caused 5 failures out of 18 tested capacitors. Failure voltages were $50 \mathrm{~V}, 79 \mathrm{~V}, 81 \mathrm{~V}, 84 \mathrm{~V}$, and $91 \mathrm{~V}$. This means that temperature changes do have an effect on these tantalum capacitors and their breakdown voltages. This should be taken into account in their use. However, none of the failures occurred under $50 \mathrm{~V}$ that is the maximum voltage given by the manufacturer.

Failed components were further examined. They were cross-sectioned and analyzed for failure by optical microscopy (shown in Figure 9). Cross-sectioning of all the failed tantalum capacitors showed redness in corners where overheating had burned the capacitors' internal materials and molding. 


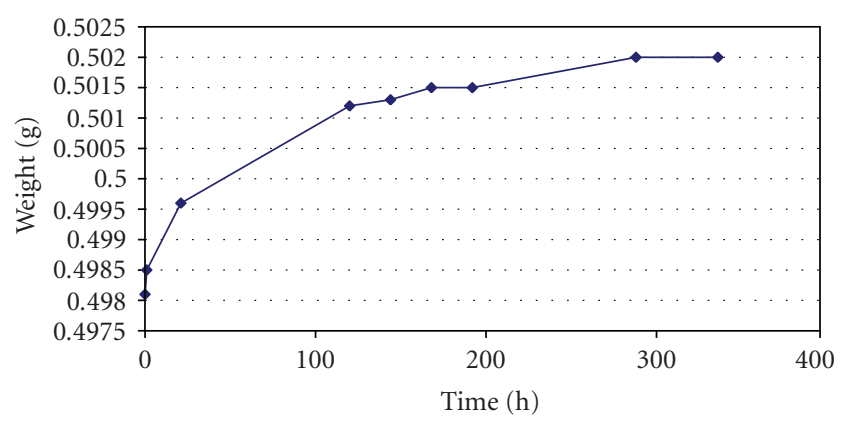

FIgURE 10: Moisture absorption in 100\% RH.

Mechanical stresses related to temperature changes have affected their performance and account for their breakdowns. Compressive forces have probably appeared on the pellet structure and produced fractures. Faults have probably occurred in the oxide. During radical temperature changes, it may have cracked with a slight shear. Even if the pellet has not fractured, there may have been enough compressive pressure for a fault site in the dielectric to grow that can develop into a breakdown spot at these lower voltages.

4.4. Effects of the 100\% Humidity Test. Results (Figure 10) show how much tantalum capacitors absorbed moisture when subjected to $100 \% \mathrm{RH}$.

The given maximum voltage for these capacitors was $50 \mathrm{~V}$, but capacitors not submitted to humidity did not fail at voltages below $93 \mathrm{~V}$. Later failures (listed in Table 2) in this test seemed to result from the absorbed moisture and soon after added voltage. After $1 \mathrm{~h}$ at $100 \% \mathrm{RH}$, there were 8 failures out of the 18 tested capacitors. However, the moisture absorption between $1 \mathrm{~h}$ and $144 \mathrm{~h}$ did not significantly affect the failure voltage, and after $144 \mathrm{~h}$, there were 9 failures out of the 18 tested capacitors. After $336 \mathrm{~h}$ at $100 \% \mathrm{RH}$, the failure rate was higher than after 144 hours, and there were 14 failures.

Mean voltages to failure with $90 \%$ confidence were calculated for capacitors (Table 3). Weibull was again used as distribution. Parameter estimation was done with maximum likelihood estimation (MLE) [36]. MLE is versatile and applicable to most models and different types of data and can be used with a data set with only few exact breakdown voltage points, such as this data that contains a lot of suspensions $[37,38]$.

The scale parameter (characteristic life; $63.2 \%$ of all values fell below it) decreased in $100 \% \mathrm{RH}$. The characteristic life for capacitors after $1 \mathrm{~h}, 144 \mathrm{~h}$, and $336 \mathrm{~h}$ was $128 \mathrm{~V}, 120 \mathrm{~V}$, and $63 \mathrm{~V}$, respectively, which means that breakdown voltage decreased as a function of time in $100 \% \mathrm{RH}$. There is no significant difference between $1 \mathrm{~h}$ and $144 \mathrm{~h}$, but after $336 \mathrm{~h}$, the breakdown voltage is much lower. The same thing can be seen with calculated mean voltages to failure that for $1 \mathrm{~h}$, $144 \mathrm{~h}$, and $336 \mathrm{~h}$, are $116 \mathrm{~V}, 113 \mathrm{~V}$, and $60 \mathrm{~V}$, respectively.

These results mean that moisture will quickly (after $1 \mathrm{~h}$ ) be absorbed inside capacitor through the moulded compound, but it takes considerable time for moisture to
TABLE 2: Breakdown voltages for 50/10-capacitors after each time in $100 \%$ RH (accuracy $\pm 1 \mathrm{~V})$.

\begin{tabular}{lccc}
\hline $0 \mathrm{~h}$ & $1 \mathrm{~h}$ & $144 \mathrm{~h}$ & $336 \mathrm{~h}$ \\
\hline$>93 \mathrm{~V}$ & $31 \mathrm{~V}$ & $23 \mathrm{~V}$ & $15 \mathrm{~V}$ \\
$>93 \mathrm{~V}$ & $34 \mathrm{~V}$ & $24 \mathrm{~V}$ & $16 \mathrm{~V}$ \\
$>93 \mathrm{~V}$ & $35 \mathrm{~V}$ & $24 \mathrm{~V}$ & $16 \mathrm{~V}$ \\
$>93 \mathrm{~V}$ & $36 \mathrm{~V}$ & $23 \mathrm{~V}$ & $17 \mathrm{~V}$ \\
$>93 \mathrm{~V}$ & $36 \mathrm{~V}$ & $30 \mathrm{~V}$ & $20 \mathrm{~V}$ \\
$>93 \mathrm{~V}$ & $39 \mathrm{~V}$ & $31 \mathrm{~V}$ & $23 \mathrm{~V}$ \\
$>93 \mathrm{~V}$ & $45 \mathrm{~V}$ & $31 \mathrm{~V}$ & $26 \mathrm{~V}$ \\
$>93 \mathrm{~V}$ & $67 \mathrm{~V}$ & $70 \mathrm{~V}$ & $26 \mathrm{~V}$ \\
$>93 \mathrm{~V}$ & $>93 \mathrm{~V}$ & $80 \mathrm{~V}$ & $28 \mathrm{~V}$ \\
$>93 \mathrm{~V}$ & $>93 \mathrm{~V}$ & $>93 \mathrm{~V}$ & $29 \mathrm{~V}$ \\
$>93 \mathrm{~V}$ & $>93 \mathrm{~V}$ & $>93 \mathrm{~V}$ & $30 \mathrm{~V}$ \\
$>93 \mathrm{~V}$ & $>93 \mathrm{~V}$ & $>93 \mathrm{~V}$ & $31 \mathrm{~V}$ \\
$>93 \mathrm{~V}$ & $>93 \mathrm{~V}$ & $>93 \mathrm{~V}$ & $31 \mathrm{~V}$ \\
$>93 \mathrm{~V}$ & $>93 \mathrm{~V}$ & $>93 \mathrm{~V}$ & $80 \mathrm{~V}$ \\
$>93 \mathrm{~V}$ & $>93 \mathrm{~V}$ & $>93 \mathrm{~V}$ & $>93 \mathrm{~V}$ \\
$>93 \mathrm{~V}$ & $>93 \mathrm{~V}$ & $>93 \mathrm{~V}$ & $>93 \mathrm{~V}$ \\
$>93 \mathrm{~V}$ & $>93 \mathrm{~V}$ & $>93 \mathrm{~V}$ & $>93 \mathrm{~V}$ \\
$>93 \mathrm{~V}$ & $>93 \mathrm{~V}$ & $>93 \mathrm{~V}$ & $>93 \mathrm{~V}$ \\
\hline
\end{tabular}

TABLe 3: Calculated mean voltages to failure (90\% Confidence), shape parameters, and scale parameters for 50/10-capacitors in $100 \% \mathrm{RH}$ test.

\begin{tabular}{lcccc}
\hline & $0 \mathrm{~h}$ & $1 \mathrm{~h}$ & $144 \mathrm{~h}$ & $336 \mathrm{~h}$ \\
\hline Upper $(90 \%)$ & $\times$ & $183 \mathrm{~V}$ & $185 \mathrm{~V}$ & $91 \mathrm{~V}$ \\
Mean & $\times$ & $116 \mathrm{~V}$ & $113 \mathrm{~V}$ & $60 \mathrm{~V}$ \\
Lower $(90 \%)$ & $\times$ & $74 \mathrm{~V}$ & $69 \mathrm{~V}$ & $40 \mathrm{~V}$ \\
$\beta$ & $\times$ & 1.4 & 1.2 & 1.1 \\
$\eta$ & $\times$ & 128 & 120 & 63 \\
\hline
\end{tabular}

affect the deeper interior of the capacitor. Moisture inside a capacitor has a lowering effect on the breakdown voltage.

Failed components were removed from the board for further examination. They were cross-sectioned and analyzed for failures by optical microscopy (Figure 11). Obviously, moisture had seeped through their epoxy covers and degraded the characteristics of the capacitor, lowering the breakdown voltage and causing a voltage breakdown. This may be because of moisture-generated silver dendrite growing on cathode contacts or because of activation of the sleeping cells. The cross-sections looked red where excessive heat had burned the internal materials and the molding of the capacitor. All capacitors failed in the same way.

\section{Conclusions}

In this paper, 4 tests were done in order to examine the effects of seacoast atmosphere on two kinds of surface mount tantalum capacitors: tantalum capacitors of a maximum voltage of $50 \mathrm{~V}$ a capacitance of $10 \mu \mathrm{F}$ and tantalum capacitors of 


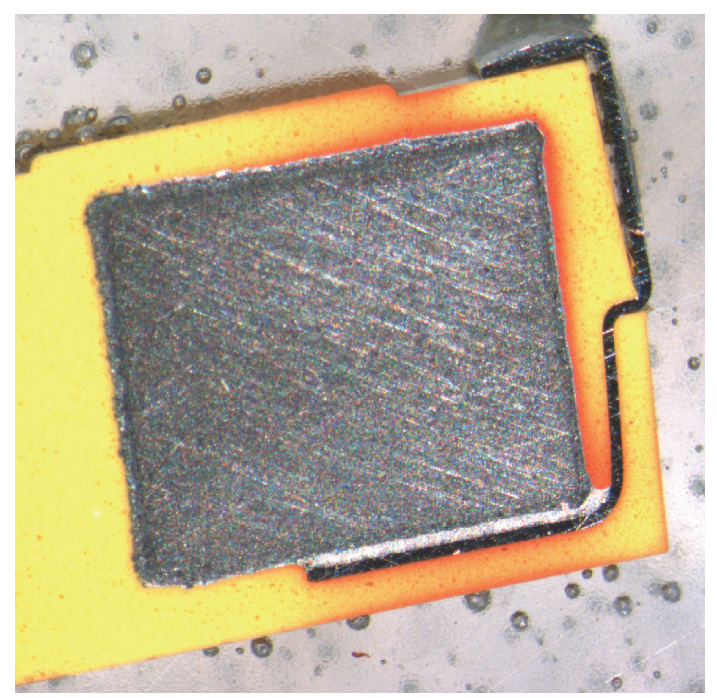

Figure 11: An example of a failed component in 100\% humidity test.

a maximum voltage of $10 \mathrm{~V}$ and a capacitance of $33 \mu \mathrm{F}$ were used.

The results show that combination of high humidity and high temperature did not possess a significant risk for $50 \mathrm{~V} / 10 \mu \mathrm{F}$ capacitors during their normal use. Very high humidity and radical temperature changes both affect the breakdown voltages of these capacitors and can cause turnon breakdowns. Salt fog caused corrosion of $10 \mathrm{~V} / 33 \mu \mathrm{F}$ capacitors but did not have an effect on capacitance or ESR. It did have a lowering effect on breakdown voltage, but the decline was not radical. These effects should be taken into account when using these tantalum capacitors at seacoast atmosphere.

\section{Acknowledgment}

J. Virkki would like to thank the Vilho, Yrjö, and Kalle Väisälä Foundation.

\section{References}

[1] T. Tekcan and B. Kirişken, "Reliability test procedures for achieving highly robust electronic products," in Proceedings of the Annual Reliability and Maintainability Symposium (RAMS '10), pp. 1-6, San Jose, Calif, USA, January 2010.

[2] R. B. Comizzoli, R. P. Frankenthal, P. C. Milner, and J. D. Sinclair, "Corrosion of electronic materials and devices," Science, vol. 234, no. 4774, pp. 340-345, 1986.

[3] W. C. Shumay, "Corrosion in electronics," Advanced Materials \& Processes Inc. Metal Progress, vol. 132, no. 3, pp. 73-77, 1987.

[4] R. Ambat and P. Møller, "Corrosion investigation of material combinations in a mobile phone dome-key pad system," Corrosion Science, vol. 49, no. 7, pp. 2866-2879, 2007.

[5] M. Tullmin and P. R. Roberge, "Tutorial corrosion of metallic materials," IEEE Transactions on Reliability, vol. 44, no. 2, pp. 271-278, 1995.

[6] R. Baboian, Ed., Corrosion Tests and Standards: Application and Interpretation, ASTM International, 2nd edition, 2005.
[7] Lifetime Data Analysis Reference, Realisoft Publishing, Tucson, Ariz, USA, 2007.

[8] A. Parviainen, J. Perälä, L. Frisk, and S. Kuusiluoma, "Connector reliability testing using salt spray," in Proceedings of the European Microelectronics and Packaging Conference (EMPC '09), p. 8, Rimini, Italy, June 2009.

[9] A. Rajan, A Review of Corrosion and Environmental Effects on Electronics, A Publication of Centre for Electronic Corrosion.

[10] P. Zhao and M. Pecht, "Field failure due to creep corrosion on components with palladium pre-plated leadframes," Microelectronics Reliability, vol. 43, no. 5, pp. 775-783, 2003.

[11] JEDEC Standard, Steady State Temperature Humidity Bias Life Test, JESD22-A101C, JEDEC Solid State Technology Association, Arlington, Tex, USA, March 2009.

[12] Finnish Standards Association SFS Standard and SFSISO9227, Corrosion Tests in Artificial Atmospheres. Salt spray tests, Federation of the Finnish Metal and Engineering Industries, Standards Department, 2001.

[13] JEDEC Standard, Temperature Cycling, JESD22-A101C, JEDEC Solid State Technology Association, Arlington, Tex, USA, 2009.

[14] D. Dias, R. Monteiro, and C. Mota-Caetano, "Study of MnO2 coverage on Ta capacitors with high CV powders," in Proceedings of the Capacitor and Resistor Technology Symposium, p. 13, 2007.

[15] H. A. Post, P. Letullier, and T. Briolat, "Failure mechanisms and qualification testing of passive components," Microelectronics Reliability, vol. 45, no. 9-11, pp. 1626-1632, 2005.

[16] J. Virkki and P. Raumonen, "Accelerated tests for the effects of power cycling on tantalum capacitors in a humid environment," Journal of Microelectronics and Electronic Packaging, vol. 7, no. 2, pp. 111-116, 2010.

[17] J. Virkki, T. Seppälä, and P. Raumonen, "Testing the effects of reflow on tantalum capacitors," Microelectronics Reliability, vol. 50, no. 9-11, pp. 1650-1653, 2010.

[18] P. Fagerholt, "A new view on failure phenomena in solid tantalum capacitors," in Proceedings of the 16th Capacitor and Resistor Technology Symposium (CARTS '96), pp. 162-166, New Orleans, La, USA, 1996.

[19] R. Dobson, "Surface mount solid tantalum capacitor new wear-out mechanism," in Proceedings of the 23rd Capacitor and Resistor Technology Symposium (CARTS '03), pp. 141-147, Scottsdale, Ariz, USA, 2003.

[20] J. Devaney, "Report on a new failure mechanism for surface mount solid tantalum capacitors," in Proceedings of the 18th Capacitor and Resistor Technology Symposium (CARTS '98), pp. 183-187, Huntington Beach, Calif, USA, 1998.

[21] A. Teverovsky, "Effect of moisture on characteristics of surface mount solid tantalum capacitors," Tech. Rep., QSS Group, Inc./Goddard Operations, NASA/GSFC, Greenbelt, Md, USA, 2003.

[22] R. B. Comizzoli, "Surface Conductance on insulators in the presence of water vapor," in Materials Developments in Microelectronic Packaging Conference, pp. 311-316, 1991.

[23] J. D. Prymak,, "Comparison of ceramic and tantalum capacitors," Tech. Rep., KEMET, 2008.

[24] J. M. Hu, D. B. Barker, A. Dasgupta, and A. K. Arora, "Role of failure-mechanism identification in accelerated testing," in Proceedings of the 1992 Annual Reliability and Maintainability Symposium, pp. 181-188, Las Vegas, Nev, USA, January 1992.

[25] E. K. Reed, "Tantalum chip capacitor reliability in high surge and ripple current applications," in Proceedings of the 44th IEEE Electronic Components ¿amp; Technology Conference (ECTC '94), pp. 861-868, Washington, DC, USA, May 1994. 
[26] Y. Freeman, R. Hahn, P. Lessner, and J. Prymak, "Reliability and critical applications of tantalum capacitors," in Proceedings of the Capacitor and Resistor Technology Symposium Europe (CARTS Europe '07), p. 11, Baecelona, Spain, 2007.

[27] T. Zednicek, J. Sikula, and H. Leibovitz, "A study of field crystallization in tantalum capacitors and its effect on DCL and reliability," Tech. Rep., AVX, 2009.

[28] S. Ezhilvalavan and T. Y. Tseng, "Conduction mechanisms in amorphous and crystalline TaO thin films," Journal of Applied Physics, vol. 83, no. 9, pp. 4797-4801, 1998.

[29] B. Long, M. Prevallet, and J. Prymak, "Reliability effects with proofing of tantalum capacitors," in Proceedings of the Capacitor and Resistor Technology Symposium (CARTS Europe '05), pp. 167-172, Prague, Czech Republic, October 2005.

[30] J. Marshall and J. Prymak, "Surge step stress testing of tantalum capacitors," in Proceedings of the 21st Capacitorsand and Resistors Technology Symposium, pp. 181-187, St. Petersburg, Fla, USA, 2001.

[31] D. M. Edson and J. B. Fortin, "Improving thermal shock resistance of surface mount tantalum capacitors ," in Proceedings of the Capacitor and Resistor Technology Symposium, pp. 169176, 1994.

[32] JEDEC Standard, Salt Atmosphere, JESD22-A107B, JEDEC Solid State Technology Association, Arlington, Tex, USA, 2004.

[33] JEDEC Standard, Preconditioning of Nonhermetic Surface Mount Devices Prior to Reliability Testing, JESD22-A113F, JEDEC Solid State Technology Association, Arlington, Tex, USA, 2009.

[34] A. Grigoriev, O. Shpyrko, C. Steimer et al., "Surface oxidation of liquid Sn," Surface Science, vol. 575, no. 3, pp. 223-232, 2005.

[35] F. Rouelle and F. Toumelin-Chemla, "Electrochemical corrosion kinetics of tin and tin amalgams in $\mathrm{NaCl}$ aqueous solutions," Journal of Solid State Electrochemistry, vol. 7, no. 3, pp. 171-176, 2003.

[36] K. C. Kapur and L. R. Lamberson, Reliability in Engineering Design, John Wiley \& Sons, 1977.

[37] W. Nelson, Accelerated Testing-Statistical Models, Test Plans, and Data Analyses, Wiley Series in Probability and Statistics, John Wiley \& Sons, 1990.

[38] B. Dodson, The Weibull Analysis Handbook, Quality Press, 2006.

[39] Reliasoft webpage, http://www.reliasoft.com/ (referred 12.1.2011).

[40] N. R. Draper and H. Smith, Applied Regression Analysis, John Wiley \& Sons, 1966. 

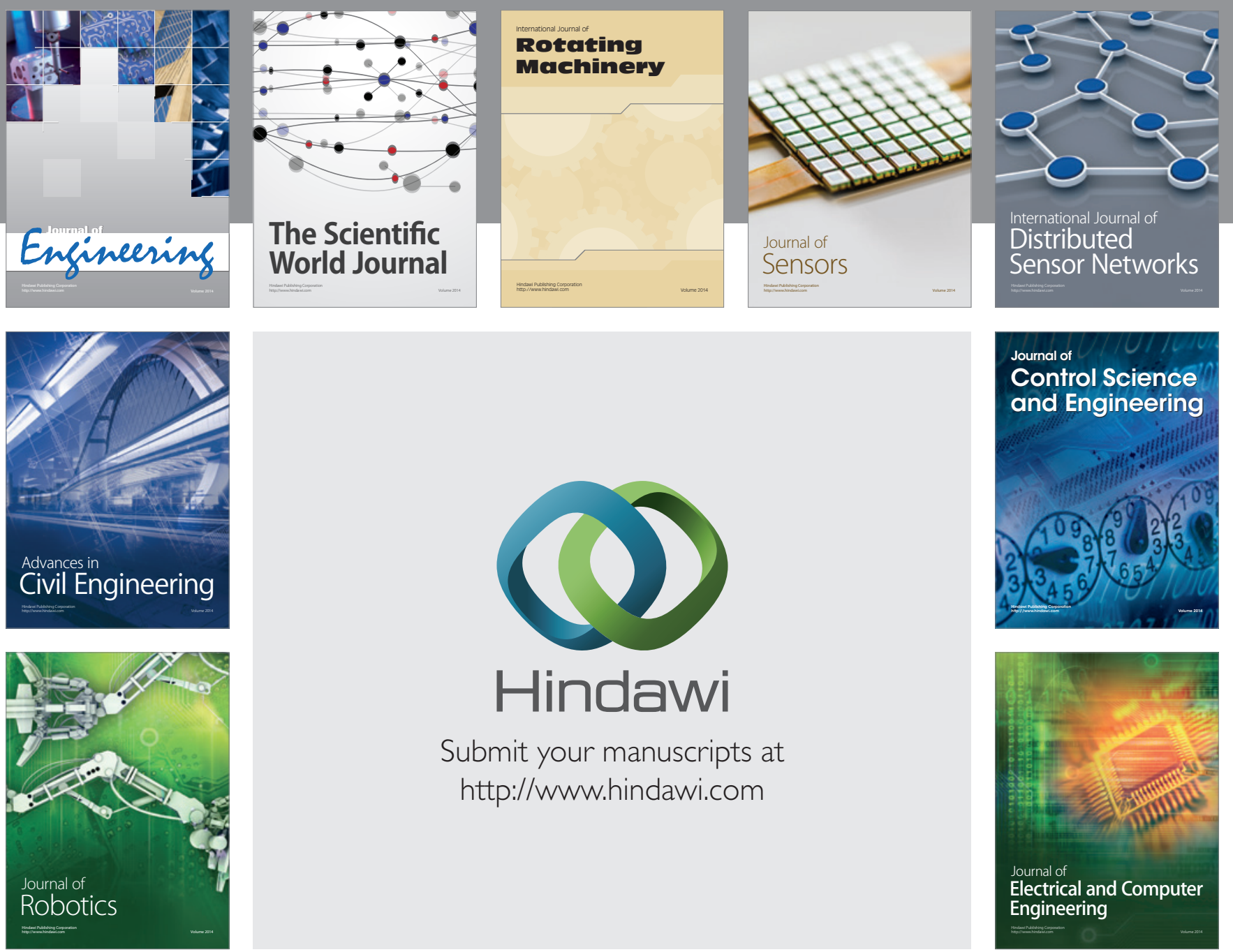

Submit your manuscripts at

http://www.hindawi.com
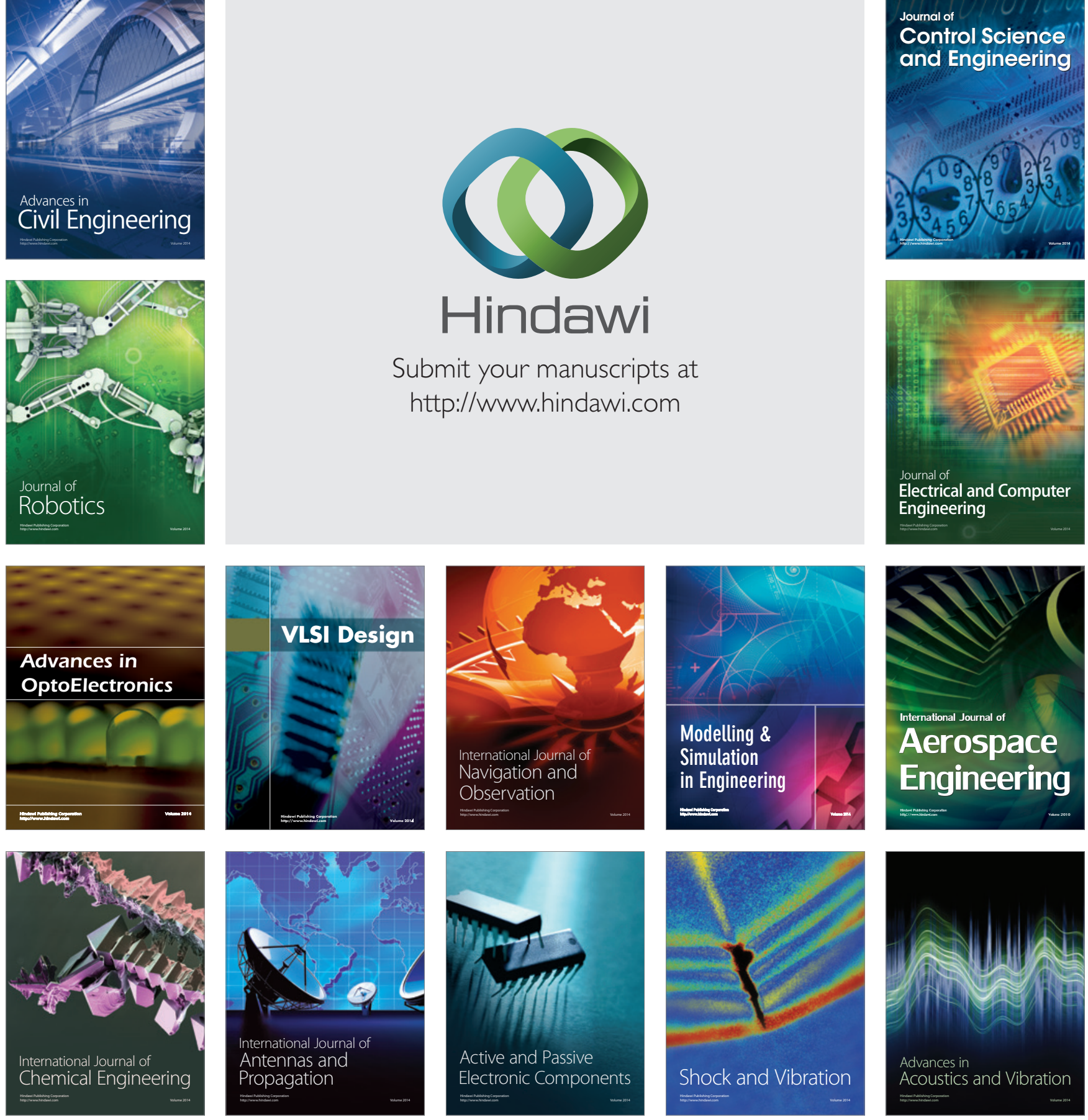